\title{
Granulocyte transfusions in haematopoietic cell transplants and leukaemia: the phoenix or beating a dead horse?
}

(c) The Author(s), under exclusive licence to Springer Nature Limited 2021

Bone Marrow Transplantation (2021) 56:2046-2049; https://doi.org/10.1038/s41409-021-01399-3

You should make a point of trying every experience once, excepting incest and folk-dancing. (and perhaps granulocyte transfusions?)

Sir Arnold Bax

Why is it some things which are so intuitive and seem easily proved continue engendering controversy and debate (Fig. 1). The example at hand is granulocyte transfusions. It has been known for $>50$ years infection risk increases precipitously in people when their blood granulocyte concentration is $<0.5 \times 10 \mathrm{E}+9 / \mathrm{L}[1,2]$ (Fig. 2). Whether, given the development of more effective systemic and oral non-absorbable antibiotics and anti-fungal drugs, often given prophylactically $0.5 \times 10 \mathrm{E}+9 / \mathrm{L}$ remains the threshold for increased infection risk or whether the threshold is closer $0-0.2 \times 10 \mathrm{E}+9 / \mathrm{L}$ is unknown. It is also possible there is no blood granulocyte nadir requiring granulocyte transfusions or where a benefit of granulocyte transfusions can be convincingly proved. Regardless, the seemingly simple remedy to decreased blood granulocytes is to transfuse granulocytes from normals or, formally, from persons with chronic myeloid leukaemia (CML). Why should granulocyte transfusions be different than RBC and platelet transfusions which are convincingly safe and effective.

The answer eluded us and granulocyte transfusions have proved a redoubtable challenge. In 1965, Profs. Gerald Bodey and the late Emil J (no period) Freireich then at the National Cancer Institute $(\mathrm{NCl})$ working with engineers at IBM developed a continuous flow centrifuge to separate other cellular other components of blood from RBCs and plasma from red blood cells. The device was named the $\mathrm{NCl} / \mathrm{IBM}$ Amino ${ }^{\mathrm{TM}}$ Continuous Flow Blood Separator [1, 3]. There were only a few in early existence, 1 at the $\mathrm{NCl}, 1$ brought to MD Anderson by Prof. Freireich where he collaborated with Dr. Jean Hester, 1 at the US Public Health (USPHS) hospital in Seattle with Reginald Clift and Prof. E. Donnell Thomas and 1 at UCLA given to me by Prof. John Fahey when he came from the $\mathrm{NCl}$. The machine was a behemoth weighing about the same as a VW bug (Fig. 3; Left). We had to sterilize the centrifuge bowel manually which took us quite some time. Occasionally they melted in the autoclave. Setting up the device between runs took about $6 \mathrm{~h}$ and we could do 2 runs at best a day. But it worked nicely and you could obtain $0.3-6 \times E+$ 10 granulocytes from a normal donor and as many as $10 \mathrm{E}+11-12$ granulocytes from a donor with chronic myeloid leukaemia (CML). In 1969, Epstein and co-workers, using an experimental model of bacteremia in dogs, reported granulocyte transfusion prolonged survival of animals with decreased granulocytes [4]. How to do this in humans? In 1977, Herzig and colleagues reported a randomized controlled trial of granulocyte transfusions obtained using the

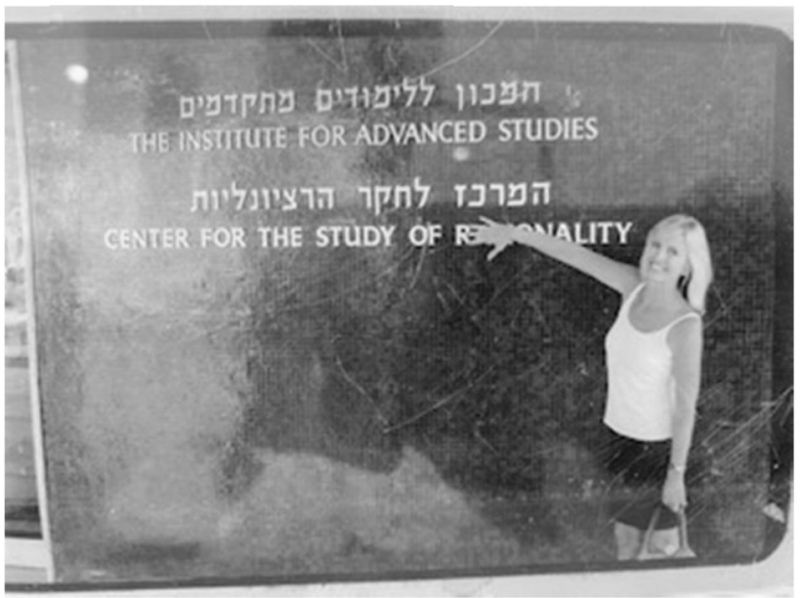

Fig. 1 Centre for the Study of Rationality. Hebrew Univ. Jerusalem.

$\mathrm{Amino}^{\mathrm{TM}}$ (now renamed Celltrifuge ${ }^{\mathrm{TM}}$ ) or by filtration leukapheresis in persons with granulocytopenia and gram-negative sepsis. Median granulocyte dose was $1 \times E+10$. The authors reported more frequent resolution of bacterial sepsis in subjects randomized to receive granulocyte transfusions obtained by either method but cautioned the most important determinant of survival was whether there was bone marrow recovery, not whether subjects received granulocyte transfusions. Makes sense, but of course you must live long enough to have bone marrow recovery. There were only 27 subjects in the study with 8 different diagnoses but they had an excellent statistician (Richard Simon; always helps). And the race was on.

The Celltrifuge ${ }^{T M}$ had other uses such as treating persons with hyper-leukocytosis and for plasmapheresis for Goodpasture and Guillain-Barré syndromes, lupus erythematosus, myasthenia gravis, thrombotic thrombocytopenic purpura, haemolytic anaemias and anything else you might think of such as multiple sclerosis. You name it. An interesting application used by Prof. Ray Powles and colleagues was collecting acute myeloid leukaemia cells to be used for auto-immunization mixed with Bacille Calmette Guerin (BCG) in an immune therapy context [5]. Sadly it failed; an idea ahead of its time? Subsequently, many smaller, more convenient blood cell separators were developed by Cobe, Haemonetics, Freseius Kabi, Terumo and others.

Beginning in the 1970s there were many uncontrolled clinical trials of granulocyte transfusions given therapeutically or prophylactically, predominately in persons with AML and haemopoietic cell transplant recipients (reviewed in [6]). Rather than belabour 


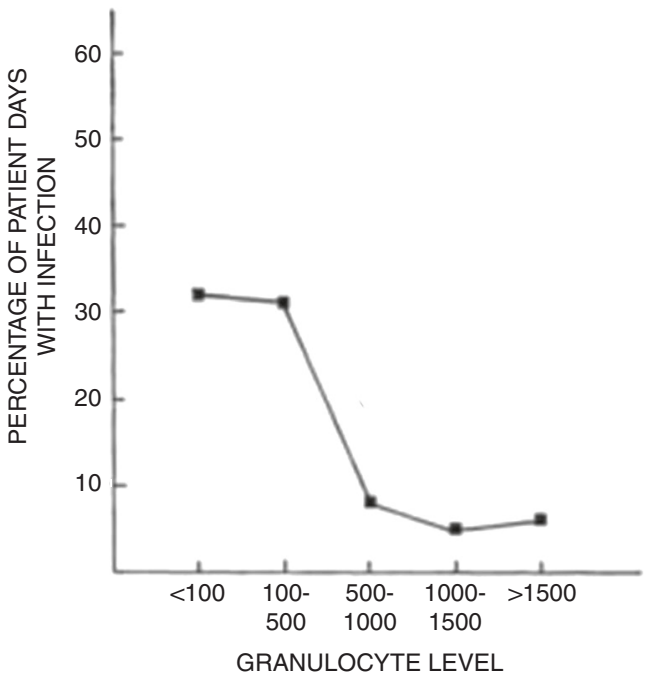

Fig. 2 Relationship between blood granulocyte concentration and infection risk [2].

the reader let's summarize by saying convincing data of safety and efficacy were lacking at best (reviewed in [7]).

In an attempt to definitively assess safety and efficacy of prophylactic granulocyte transfusions in persons with AML receiving intensive induction chemotherapy investigators from several US centres including 1 of us (RPG) conducted a large randomized controlled trial [8]. We found granulocyte transfusions did not reduce infection incidence, increase remission rate or improve survival. Although the incidence of bacterial septicaemia was decreased that of pulmonary infiltrates increased and transfusion reactions were common. Others reported high rates of allo-immunization to HLA- and granulocyte-specific histocompatibility antigens resulting in decreased efficacy of platelet transfusions, transfusion reactions and sequestration of granulocytes in the lungs compromising pulmonary function [9]. The interaction between granulocyte transfusions and amphotericin was particularly nasty. We and others concluded prophylactic granulocyte transfusions should not be used during remissioninduction chemotherapy in AML because risks outweighed benefits.

After these data were published use of prophylactic and therapeutic granulocyte transfusion decreased markedly and the issue seemed settled. But not so fast. In 2006, one of us (CAS) published an article titled: Granulocyte transfusion therapy 2006: The comeback kid? Apparently not. Granulocyte transfusion remained a boutique practice. A PUBMED search on 1 May 2021 of granulocyte transfusions restricted to clinical trials identified 699 citations displayed in Fig. 4 cresting in 1999 with a substantial decline thereafter.

We wondered why. The answer came quickly. On a recent ZOOM call with members of the American Society of Transplantation and Cellular Therapy (ASCT) Sub-Committee on Supportive Care composed of transplant, transfusion and blood bank experts, the question was raised whether we should develop a consensus recommendation on the use of granulocyte transfusions in haematopoietic cell transplant recipients. We were amazed to learn from almost all participants they gave granulocyte transfusions to people with what were judged to be antibiotic unresponsive infections. Put aside the questionable validity of consensus recommendations, Abba Eban said: $A$ consensus means everyone agrees to say collectively what no one believes individually [10]. It seemed a bit like the notion no one should be allowed to die without receiving high-dose corticosteroids. So, back to a 1990-present Boolean search on PUBMED, this time with granulocyte transfusions AND randomized controlled trials. There were only 2 citations, the 1st, remarkably by Prof. Freireich in 2013 when he was 86 years old, 47 years after he reported developing the Aminco ${ }^{\text {TM }}$ Blood Cell Separator [11] with $\mathrm{NCl}$ and IBM colleagues. Prof. Freireich, who was not fond of randomized controlled trials [12], reported a study of 103 subjects with acute leukaemia with life-threatening infections refractory to antibiotics given unirradiated or irradiated WBC transfusions. Survivals were comparable. Disappointingly, but not surprisingly, there was no control cohort of subjects receiving no granulocyte transfusions. One is reminded of the quote from Samuel Butler: He that complies against his will is of his own opinion still which he may adhere to, yet disown, for reasons to himself best known [13]. (RPG was horrified to realize he was the Editor who accepted the typescript for publication in LEUKEMIA.) The 2nd randomized control trial had the promise of being more informative. Investigators randomized 114 subjects with proven/probable/presumed bacterial or fungal infection and granulocytes $<0.5 \times 10 \mathrm{E}+9 / \mathrm{L}$ to anti-microbial therapy with or without granulocyte transfusions [14]. Granulocytes were obtained from normal donors given granulocytecolony stimulating factor (G-CSF) so the transfused granulocyte dose was considered high (see below). However, no convincing benefit was reported. Although the sample size might be considered small, any effect size was similarly small. Several meta-analyses and systematic reviews also concluded there was no convincing benefit of granulocyte transfusions in these settings [15-17]. Regardless, there is even an international registry of granulocyte transfusions [18]. It has data on 80 subjects.

If granulocyte transfusions make so much sense why do they repeatedly fail in randomized controlled trials? Reasons are myriad including (1) Dose: Normal daily granulocyte production is $5-10 \times$ $10 \mathrm{E}+10$ but can increase 4-fold during an infection. Doses achieved in normal donors given G-CSF are $5.5 \times 10 \mathrm{E}+10$ substantially lower than the normal physiologic response to infection; (2) Lifespan: The brief lifespan of granulocytes is such that transfusions have to be given daily or more frequently until bone marrow recovery. The lifespan of granulocytes in normals is controversial [19]. It is thought to be a few days but decreases to hours or minutes in infected person necessitating frequent transfusions to be effective; (3) Distribution: About one-half of granulocytes in a normal person are in a marginal pool [20]. In infected persons granulocytes accumulate at sites of infection rather than in the blood [21]; and (4) Allo-immunization: It is likely most subjects in the randomized controlled trials we cite were allo-immunized (histocompatibility testing was not routinely done in most studies). Studies using ${ }^{111}$ indium-labelled granulocytes indicate impaired migration of transfused granulocytes to sites of infection in allo-immunized persons suggesting transfusions are likely to be ineffective this setting [22]; and (5) Logistics: There are logistic issues for donors, apheresis personnel, clinicians and recipients all of whom must be mobilized on short notice. These considerations illustrate concerns for the use of granulocyte transfusions despite anecdotal reports of success.

There are several other important practical considerations. First, as we discussed above, with the use of modern anti-microbials and given preventively and/or therapeutically and or oral nonabsorbable antibiotics it is unproved there is a nadir blood granulocyte concentrations where granulocyte transfusions are needed and/or would be effective. Recent clinical trials in older persons receiving intensive induction chemotherapy for acute myeloid leukaemia (AML) report rates of deaths $<30$ days) are only $5-10 \%$ [23]. Consequently, a randomized trial of granulocyte transfusions in this setting which reduced deaths by one-half $(10 \%$ versus $5 \%$ ) with a $P_{a}=0.5$ and a $P_{\beta}=0.80$ would require 868 evaluable subjects including 434 receiving granulocyte transfusions, clearly an undoable study. Second, the key determinant of recovery from an uncontrolled infection is bone marrow recovery. In the context of haematopoietic cell transplants there is usually bone marrow recovery within about 10 days and even briefer in 

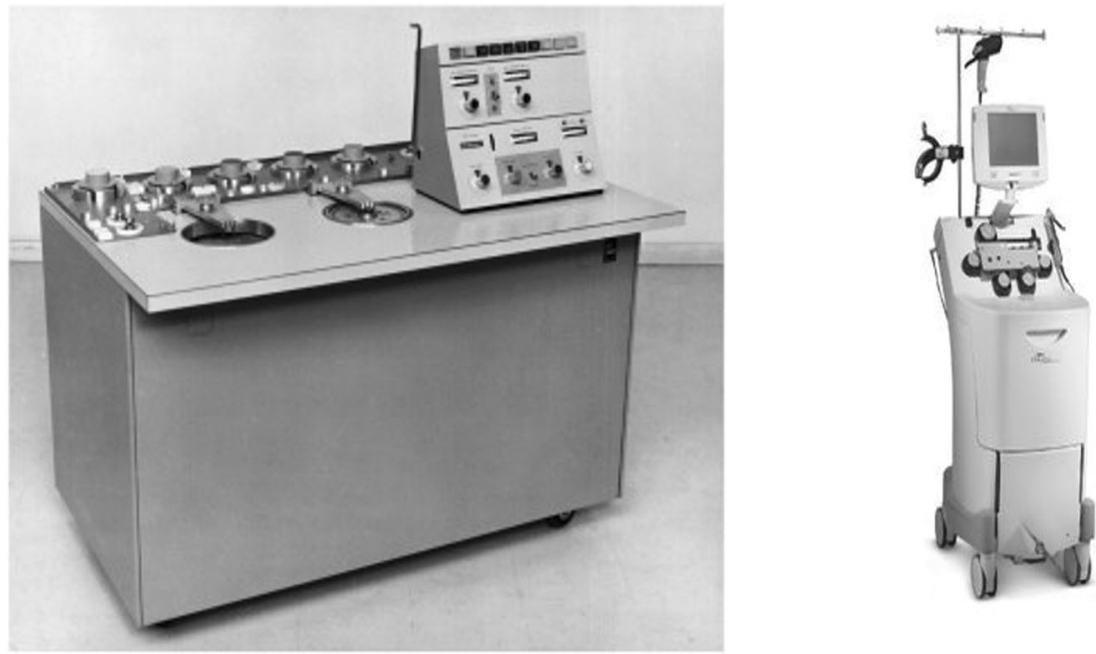

Fig. $3 \mathrm{NCl} / \mathrm{IBM}$ Amino ${ }^{\mathrm{TM}}$ Continuous Flow Blood Separator (L) and modern blood cell separator (R).

RESULTS BYYEAR

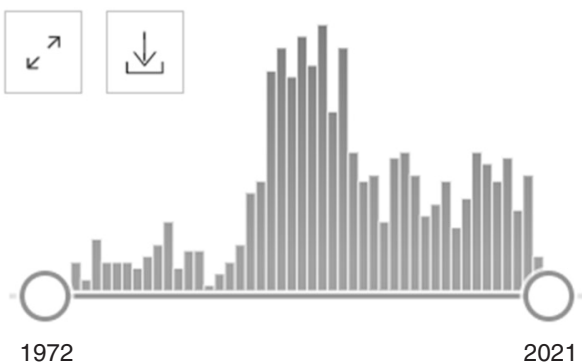

Fig. 4 Citations of clinical trials of granulocyte transfusions by year in PUBMED.

persons receiving molecularly-cloned myeloid growth factor mobilized blood cell grafts, reduced-intensity conditioning (RIC) transplants and in autotransplant recipients. As such it is unlikely granulocyte transfusions are needed except possibly in persons with primary graft-failure, a relatively rare event in haematological cancers. Third, prolonged bone marrow failure is most common in persons receiving 2 nd or $3 \mathrm{rd}$ line therapies for resistant or relapsed haematological cancers. These persons are unlikely to achieve a sustained anti-cancer response to these interventions and likely to die from their underlying cancer regardless of whether or not a resistant infection is treated successfully with granulocyte transfusions. Fourth, it's difficult or impossible to do required testing for infectious agents in donors and in granulocyte transfusion concentrates given the brief lifespan or collected granulocytes from normal donors. Fifth, there is the important consideration of donor safety, especially of repeat donors, when giving them molecularly-cloned myeloid growth factors and corticosteroids, especially to facilitate an unproved intervention. Lastly, few medical centres are willing or able to commit the resources and personnel needed to activate daily or even twice daily granulocyte transfusions for the occasional persons who might benefit.

So where does this leave us in 2021, 343 years after Samuel Butler, 115 after Sir Ralph Bloomfield Bonington commented in The Doctor's Dilemma: Stimulate the phagocytes, drugs are a delusion, 56 years after developing the Aminco ${ }^{T M}$ blood cell separator and 6 years after the last randomized controlled trial? [24] Our rejoinder: little has changed. Are we experiencing a triumph of hope over reason? Although there are no convincing data of safety or efficacy of granulocyte transfusions we concede the absence of evidence is not evidence of absence. Granulocyte transfusions remain a seemingly logical therapy of resistant infections in persons with granulocytopenia. People want to believe they are safe and effective despite no convincing data and some data suggesting they are neither. So much for evidencebased medicine. We are certain incest and folk dancing are to be assiduously avoided. As for granulocyte transfusions: caveat emptor. For additional reading we recommend Feeling Smart: Why Our Emotions Are More Rational Than We Think by Eyal Winter.

\section{Robert Peter Gale ${ }^{1 凶}{ }^{凶}$, Charles A. Schiffer ${ }^{2}$ and Hillard M. Lazarus (D) $^{3}$}

${ }^{1}$ Haematology Research Centre, Department of Immunology and Inflammation, Imperial College London, London, UK. ${ }^{2}$ Karmanos Cancer Institute, Wayne State University School of Medicine Detroit, Detroit, MI, USA. ${ }^{3}$ Department of Medicine, Division of Hematology and Oncology, Case Western Reserve University, Cleveland, OH, USA.

凶email: robertpetergale@alumni.ucla.edu

\section{REFERENCES}

1. Freireich EJ, Judson G, Levin RH. Separation and collection of leukocytes. Cancer Res. 1965;25:1516-20.

2. Bodey GP, Buckley M, Sathe YS, Freireich EJ. Quantitative relationships between circulating leukocytes and infection in patients with acute leukemia. Ann Intern Med. 1966;64:328-40.

3. Oon CJ, Hobbs JR. Clinical applications of the continuous flow blood separator machine. Clin Exp Immunol. 1975;20:1-16.

4. Epstein RB, Clift RA, Thomas ED. The effect of leukocyte transfusions on experimental bacteremia in the dog. Blood. 1969;34:782-90.

5. Powles RL, Russell JA, Selby PJ, Prentice HG, Jones DR, McElwain TJ, et al. Maintenance of remission in acute myelogenous leukaemia by a mixture of B.C.G. and irradiated leukaemia cells. Lancet. 1977;26:1107-10.

6. West KA, Conry-Cantilena C. Granulocyte transfusions: current science and perspectives. Semin Hematol. 2019;56:241-7.

7. Schiffer CA. Granulocyte transfusion therapy 2006: the comeback kid? Med Mycol. 2006;44:S383-S386. https://doi.org/10.1080/13693780600752499.

8. Strauss RG, Connett JE, Gale RP, Bloomfield CD, Herzig GP, McCullough J, et al. A controlled trial of prophylactic granulocyte transfusions during initial induction chemotherapy for acute myelogenous leukemia. $N$ Engl J Med. 1981;305:597-603.

9. Schiffer CA, Aisner J, Daly PA, Schimpff SC, Wiernik PH. Alloimmunization following prophylactic granulocyte transfusion. Blood. 1979;54:766-74.

10. Barosi G, Gale RP. Is there expert consensus on expert consensus? Bone Marrow Transpl. 2018;53:1055-60.

11. Freireich EJ, Lichtiger B, Mattiuzzi G, Martinez F, Reddy V, Kyle Wathen J. A prospective, randomized, double-blind study, comparing unirradiated to 
irradiated white blood cell transfusions in acute leukemia patients. Leukemia. 2013;27:861-5.

12. Gale RP, Emil J. Freireich and Baruch Spinoza: birds of a feather? Leukemia. 2021. https://doi.org/10.1038/s41375-021-01216-2.

13. Hudibras BS. Written in the time of the late wars. Cambridge Univ. Press. 1905. Part III, Canto iii, lines 547-50.

14. Price TH, Boeckh M, Harrison RW, McCullough J, Ness PM, Strauss RG, et al. Efficacy of transfusion with granulocytes from G-CSF/dexamethasone-treated donors in neutropenic patients with infection. Blood. 2015;126:2153-61.

15. Vamvakas EC, Pineda AA. Meta-analysis of clinical studies of the efficacy of granulocyte transfusions in the treatment of bacterial sepsis. J Clin Apher. 1996;11:1-9.

16. Vamvakas EC, Pineda AA. Determinants of the efficacy of prophylactic granulocyte transfusions: a meta-analysis. J Clin Apher. 1997;12:74-81.

17. Estcourt $\sqcup$, Stanworth S, Doree C, Blanco P, Hopewell S, Trivella M, et al. Granulocyte transfusions for preventing infections in people with neutropenia or neutrophil dysfunction. Cochrane Database Syst Rev. 2015;6:CD005341.

18. Pagano MB, Morton S, Cohn CS, Gross S, Kutner J, Lewin A, et al. An international registry of granulocyte transfusions. Transfus Med Hemother. 2018;45:318-22.

19. Hidalgo A, Chilvers ER, Summers C, Koenderman L. The neutrophil life cycle. New Advances in Neutrophil. Immunity. 2029;40:584-97.

20. Athens JW, Raab SO, Haap OP, Mauer AM, Ashenbrucker H, Cartwright GE, et al. Leukokinetic studies. III. The distribution of granulocytes in the blood of normal subjects. J Clin Invest. 1961;40:159-64.

21. Dutcher JP, Schiffer CA, Johnston GS, Papenburg D, Daly PA, Aisner J, et al. Alloimmunization prevents the migration of transfused 111 Indium-labeled granulocytes to sites of infection. Blood. 1983;62:354-60.

22. Dutcher JP, Kendall J, Norris D, Schiffer C, Aisner J, Wiernik PH. Granulocyte transfusion therapy and amphotericin B: adverse reactions? Am J Hematol. 1989;31:102-8

23. Lancet JE, Uy GL, Cortes JE, Newell LF, Lin TL, Ritchie EK, et al. CPX-351 (cytarabine and daunorubicin) liposome for injection versus conventional cytarabine plus daunorubicin in older patients with newly diagnosed secondary acute myeloid leukemia. J Clin Oncol. 2018;36:2684-92.
24. Shaw B. The doctor's dilemma: getting married, \& the shewing-up of Blanco Posnet. Constable; 1911.

\section{ACKNOWLEDGEMENTS}

RPG acknowledges support from the National Institute of Health Research (NIHR) Biomedical Research Centre funding scheme.

\section{COMPETING INTERESTS}

RPG is a consultant to Ascentage Pharma Group, BeiGene Ltd., Kite Pharma Inc., Fusion Pharma LLC, LaJolla NanoMedical Inc., NexImmune Inc., Mingsight Parmaceuticals Inc., Prolacta Bioscience, Inc. and CStone Pharmaceuticals; Medical Director, FFF Enterprises Inc.; Partner, AZCA Inc.; Board of Directors, RakFond Foundation for Cancer Research Support; Scientific Advisory Board, Antegene Biotech LLC and StemRad Ltd. HML is a consultant to Partner Therapeutics and Pluristem Therapeutics, Actinium Pharmaceuticals, Jazz Pharmaceuticals, Seattle Genetics, a member of the Data Safety Monitoring Boards for Bristol-Myers Squibb-Celgene and BioSight, and a promotional speaker for AstraZeneca, Seattle Genetics and Jazz Pharmaceuticals.

\section{ADDITIONAL INFORMATION}

Correspondence and requests for materials should be addressed to R.P.G.

Reprints and permission information is available at http://www.nature.com/ reprints

Publisher's note Springer Nature remains neutral with regard to jurisdictional claims in published maps and institutional affiliations. 